Ensino, Saúde e Ambiente - V6 (3), pp. 1-20, dez. 2013

\title{
CONTRIBUIÇÕES DA ALFABETIZAÇÃO CIENTÍFICA E TECNOLÓGICA PARA A EDUCAÇÃO AMBIENTAL NO ENSINO MÉDIO: UM ESTUDO DIAGNÓSTICO.
}

\section{CONTRIBUTIONS OF SCIENTIFIC AND TECHNOLOGICAL LITERACY FOR ENVIRONMENTAL EDUCATION IN HIGH SCHOOL: A DIAGNOSTIC STUDY.}

\author{
Reginaldo dos Santos ${ }^{1}$ e Rita de Cássia Frenedozo ${ }^{2}$ \\ ${ }^{1}$ Doutorando do Programa de Pós-graduação e Pesquisa da Universidade Cruzeiro do Sul - UNICSUL, \\ São Paulo - reginaldousp@hotmail.com \\ ${ }^{2}$ Professora do Programa de Pós-graduação e Pesquisa da Universidade Cruzeiro do Sul - UNICSUL, São \\ Paulo - rita.frenedozo@cruzeirodosul.edu.br
}

\section{RESUMO}

Esse artigo é parte dos estudos preliminares para uma tese de doutorado que objetiva compreender a Alfabetização Científica e Tecnologia (ACT) como finalidade da Educação Científica, e também, investigar fundamentos e métodos de ensino que possam contribuir com a sua promoção na Educação Básica, ressaltando aí, aqueles que também favorecem a promoção da Educação Ambiental (EA). Assim, tal artigo relata um estudo de abordagem quali-quantitativa, caracterizado como pesquisa descritiva e de campo, desenvolvido em 2012, com o objetivo de identificar percepções e concepções de alunos do Ensino Médio acerca de fatores relacionados à Educação Ambiental. Para coletar dados/informações usou-se produção de texto e a fundamentação bibliográfica ancorou-se nos trabalhos de Cachapuz et al. (2005) e Carvalho (2011), entre outros autores que discorrem sobre a emergência da ACT e da EA na atualidade. Os resultados alcançados favorecem o discurso que preconiza a ACT como finalidade da Educação Científica na Educação Básica.

Palavras-chave: Alfabetização Científica e Tecnológica; Educação Científica; Educação Ambiental.

\begin{abstract}
This article is part of the preliminary studies for a doctoral thesis which aims to understand the Scientific Literacy and Technology (SLT) as the aim of science education, and also to investigate fundamentals and teaching methods that can contribute to its promotion in basic education, emphasizing there, those who also favor the promotion of Environmental Education (EE). Thus, this paper reports a study of qualitative and quantitative approach, characterized as a descriptive and field, developed in 2012, with the objective to identify perceptions and conceptions of high school students about factors related to environmental education. To collect data/information used to produce text and bibliographic foundation was anchored in the works of Cachapuz et al. (2005) and Carvalho (2011), among other authors who talk about the emergence of SLT and EE today. The results obtained favor the speech that advocates the SLT as the aim of Science Education in Basic Education.
\end{abstract}

Key words: Scientific and Technological Literacy; Science Education; Environmental Education. 


\section{Introdução}

Frente as diferentes opções de vertentes de abordagem que a temática da Educação Ambiental (EA) oferece às ações educativas de ensino formal e não formal que visam a sua promoção, neste artigo propõe-se discutir tal educação pela vertente que discorre sobre o ensino formal, em especial, o Ensino de Ciências da Educação Básica, que nesse manuscrito, será denominado por Educação Científica em razão da ênfase e amplitude que se deseja imprimir sobre a função de tal ensino como contributo à formação cidadã para o pleno exercício da cidadania.

Sem desconsiderar a importância da interdisciplinaridade defendida por Reigota (2009), entre outros autores, como meio favorável à consolidação da Educação Ambiental e, da mesma forma, sem desconsiderar a importância da transversalidade orientada pelos Parâmetros Curriculares Nacionais (PCN) Brasil (1998a; 1998b) também como meio favorável e necessário à promoção da EA, tal opção de vertente de discussão sobre essa educação está atrelada ao entendimento que a Educação Científica do âmbito da Educação Básica, necessita assumir expressivamente sua parcela de obrigação sobre a promoção da EA valendo-se fortemente do seu objeto de estudo (a natureza), na perspectiva de, por um lado, uma EA menos ingênua, superficial, dogmática e/ou equivocada, e por outro, uma Educação Científica mais comprometida com a ética e com as questões sociais e ambientais.

Em ponto inicial, sinaliza-se que aqui não se pretende advogar contra ou em defesa da interdisciplinaridade, da disciplinaridade ou da transversalidade, o que se perspectiva é discorrer sobre a necessidade de o ensino formal - que no momento, na sua quase totalidade, no contexto brasileiro, ainda se organiza por disciplinas escolares - se organizar de forma menos linear e cartesiana, sem abrir mão do seu potencial de entendimento profundo sobre a sua área de estudo, para dai contribuir com uma EA pautada na ética, na política e na conscientização do como a(s) ideologia(s), se apresenta(m) frente a esses jogos de interesses.

Aprofundando um pouco mais a interpretação apresentada nos parágrafos anteriores, entende-se que a Educação Científica para a EA tem suas obrigações aumentadas na medida em que a globalização e os avanços científicos e tecnológicos consolidam-se, impulsionando o consumismo e alterando os modos e perfis sociais de viver e conviver, o que, provavelmente, exige da escola enquanto legítima instituição social criada para influenciar e ser influenciada por transformações sociais, uma atuação 
mais coerente com esses novos perfis, para assim, ser mais útil e significativa para a sociedade e para o máximo possível de alunos, se não, todos.

Fundamentando-se em Cachapuz et al. (2005) e Demo (2011), ao afirmar que o ensino escolar necessita ser significativo e útil para todos os alunos, independentemente de estes, desejarem ou não, seguir uma ou outra carreira e/ou nível mais elevado de estudo e formação, entende-se que, para tal ensino ser de fato útil, tanto para a vida no plano individual (o pessoal), como no plano coletivo (o social que é a vida enquanto cidadão), é necessário que a educação escolar se desenvolva também por meio de um pluralismo metodológico ${ }^{1}$ com perspectiva de um processo ensino-aprendizagem mais formativo (predomínio na abordagem temática), em substituição ao ensino informativo (predomínio na abordagem conceitual) que ainda fortemente ocupa o cerne do processo ensino-aprendizagem, mesmo sem ser, direta ou indiretamente, em muitas ocasiões, desejado pelos professores e alunos da sociedade contemporânea.

Mediante ao que aqui nesse artigo vem sendo apresentado, então, tem-se a seguinte interpretação: para termos uma EA coerente com o que se apregoa com, por um lado, o regime democrático de governo, e por outro, com o modelo de progresso que, ao menos em tese, é almejado com o desenvolvimento sustentável, entende-se que é necessário que todo cidadão, independente da sua idade, classe e segmento social, obtenha formação que o torne desgarrado de ideias românticas, dogmáticas, autoritárias, ingênuas e/ou superficiais sobre as questões ambientais, para assim, assumir de fato, sua parcela de responsabilidades individual e coletiva na efetiva contribuição para a conservação da natureza e uso correto do meio ambiente e dos recursos naturais de uma forma geral (BARBIERI, 2009; LEFF, 2010; CARVALHO, 2011; SOFFIATI, 2011).

Concordando com Tozoni-Reis (2003), Leff (2010) e Carvalho (2011), entendese que a EA não pode ser concebida, principalmente pelo processo ensino-aprendizagem escolar, como um doutrinamento para modificar comportamentos ambientais predatórios. Ela necessita ser caracterizada como um processo de entendimento profundo sobre a construção da relação humana com o meio ambiente, onde, os princípios da responsabilidade democrática e ética devem sempre estar presentes em todas as discussões e opções que se faz, tanto no âmbito individual (o sujeito), como em outros segmentos que compõem as atividades e organizações sociais da comunidade humana (o Governo, o Estado, a Ciência, a Tecnologia, a Sociedade, a Indústria...).

\footnotetext{
${ }^{1}$ Termo ricamente discutido em LABURÚ, C.E.; CARVALHO, M. Educação científica: controvérsias construtivistas e pluralismo metodológico. Londrina: Eduel, 2005.
} 
Segundo Santos (2011), conforme o enfoque de atuação da EA sobre o processo formativo do sujeito que os diferentes autores desejam salientar, então, o discurso dessa educação aparece nas publicações nacionais e estrangeiras por meio de diferentes visões de interpretações acerca da sua definição, finalidade e perspectiva (a perspectiva conservadora e a perspectiva crítica, por exemplo). Assim, como também se discorre em Cachapuz et al. (2005), aqui nesse artigo, o foco de discussão ancora-se em uma percepção e concepção de EA que necessita ser promovida/facilitada pela Educação Científica do processo ensino-aprendizagem escolar do ensino formal que por sua vez, deve incorporar uma visão (auto)crítica, consciente e democrática sobre o uso dos recursos naturais e as complexas causas de degradação ambiental como o Capitalismo, a Modernidade, o Industrialismo, a Urbanização, a Ciência e a Tecnologia.

Com esse foco de discussão sobre a EA aqui recortado, então, acredita-se que para termos a efetivação/consolidação de uma EA coerente com o perfil social contemporâneo (perfil este influenciado fortemente pela Ciência e a Tecnologia), a Educação Científica para a Educação Básica, balizada pela Alfabetização Científica e Tecnológica (ACT), pode oferecer importantes contribuições para a EA que atualmente se almeja para a sociedade contemporânea como vem sendo apregoado por meio das diferentes publicações de leis, estudos e documentos oficiais como por exemplo a Lei 9.795/99 que dispõe sobre a EA e institui a Política Nacional de EA no Brasil.

As concepções de entendimento sobre Alfabetização Científica e ACT adotadas nesse artigo ancoram-se nas concepções apresentadas por Chassot $(2008 ; 2010)$, Auler (2003), Fourez (2005) e Sasseron e Carvalho (2011) onde tais concepções trazem em seu cerne de discussão o desejo por uma Educação Científica que por sua vez seja capaz de contribuir com o processo formativo de competências e habilidades necessárias à compreensão básica de termos, conhecimentos e conceitos científicos e tecnológicos fundamentais, compreensão da natureza da Ciência e da Tecnologia e dos fatores éticos e políticos que circundam suas práticas, e ainda, entendimento das relações e/ou interações existentes entre a Ciência, a Tecnologia, a Sociedade e o Meio Ambiente.

$\mathrm{O}$ entendimento sobre a necessidade de uma Educação Científica com vista à ACT se justifica ao passo que a Ciência e a Tecnologia avançam impulsionadas uma pela outra através de uma interação cujo produto final representará sempre mais potencial de interação e propulsão recíproca, coadunando na influência sobre o perfil de vida da sociedade e as causas/questões ambientais em geral (AULER, 2003; UNESCO, 2003; CHASSOT, 2010). 
Tem-se esse entendimento de necessidade educacional ao ser percebido que, se por um lado os avanços científicos e tecnológicos trouxeram progresso e melhoria para a qualidade de vida de boa parte da humanidade, por outro, esses mesmos avanços também provocaram, e vem provocando, destruição acelerada da natureza porque também influencia o consumismo desenfreado de bens não duráveis, aumento da produção de lixo de difícil biodegradação, bem como, aumento da necessidade de extração de recursos naturais, inclusive aqueles classificados como não renováveis e/ou de difícil renovação (UNESCO, 2003).

É sabido por muitos que a influencia da Tecnologia sobre o modo de vida da Sociedade, em muitas situações, se dá de forma tão contundente, no sentido decisivo que, é como se as necessidades das pessoas, surgissem em função da Tecnologia, quando deveria ser o contrário (ACEVEDO-DÍAZ; VÁZQUEZ-ALONSO e MANASSERO-MAS, 2003; PINHEIRO; SILVEIRA; BAZZO, 2009; DEMO, 2011).

Decidir pela compra e consumo de produtos, levando-se em conta não só a eficiência desses para fins que se deseja, mas também, os seus efeitos sobre a saúde e o ambiente, seu valor econômico e as questões relacionadas à sua produção e comercialização, provavelmente, são comportamentos e atitudes que, para ocorrer satisfatoriamente, necessitam de uma formação básica pautada na ética e em um básico de conhecimento sobre a natureza da Ciência e da Tecnologia, bem como, dos interesses que subjaz os avanços científicos e tecnológicos, como por exemplo, vem sendo discutido/debatido por meio do enfoque Ciência-Tecnologia-Sociedade, o enfoque CTS que também é apresentado por alguns autores em publicações nacionais e estrangeiras, com a denominação de enfoque Ciência-Tecnologia-Sociedade-Ambiente (enfoque CTSA) (SANTOS; MORTIMER, 2001; SANTOS, 2011).

Exemplos do expressivo poder de influência da Ciência e da Tecnologia sobre a forma como os fatos e problemas da sociedade são interpretados, conduzidos e/ou resolvidos, como é o caso, por exemplo, das técnicas de aconselhamento genético, produção de organismos transgênicos, reprodução assistida, clonagem, uso de célulastronco, estudo do genoma humano, uso de teste de DNA para diversos fins, são também discutidos pelas pesquisadoras brasileiras Lygia da Veiga Pereira em seu livro: Sequenciaram o genoma humano... e agora? e, Mayana Zatz em seu livro: Genética: escolhas que nossos avós não faziam, acerca dos avanços científicos e tecnológicos, e como na visão dessas pesquisadoras, tais avanços devem ser interpretados e processados/usados/pretendidos, tanto por parte da Comunidade Científica, Governo, 
Estado, Sistema Econômico-Financeiro-Industrial, bem como, pela Sociedade em geral. Assim, na visão dessas pesquisadoras, os avanços da Ciência e Tecnologia estão aí, vieram para ficar e tendem à expansão progressiva, exigindo de toda a sociedade, o seu entendimento para o seu uso responsável, democrático, ético e consciente.

Quando se fala em uso democrático do conhecimento científico e tecnológico e seus produtos, entende-se que se pode constituir o seguinte entendimento: ao optar-se pela democracia como regime de governo, acredita-se que a ACT como finalidade da Educação Científica como aqui está sendo concebida, pode ser vista também como um dos meios para se legitimar o desejo pela conservação de tal regime de governo. Ou seja, não se tem democracia sem participação direta e/ou indireta de todo o povo e, entende-se que, para participar de decisões é necessário se ter um mínimo/básico possível de conhecimento sobre o que se discute, opta-se e/ou está em jogo, e assim, ser menos vulnerável as ideologias ${ }^{2}$ dominantes.

\begin{abstract}
Provavelmente, não há um único projeto científico hoje em dia que possa ser desenvolvido sem dinheiro do governo. Por outro lado, nenhuma decisão governamental importante pode ser tomada e implementada sem uma pesquisa científica preliminar e sem uma monitoração científica constante [...] Praticamente não existe nenhuma área da atividade governamental ou de desenvolvimento industrial privado em que os cientistas não marquem presença [...] (FERRAROTTI, 1998, p. 61).
\end{abstract}

Sobre o que foi apresentado nos dois últimos parágrafos, cita-se como exemplo as recentes discussões para a aprovação do Novo Código Florestal brasileiro em que, na ocasião, abriu-se oportunidade de participação direta de todos os segmentos da sociedade, mas as orientações oriundas das pesquisas científicas apareceram fortemente no discurso do Governo como os caminhos, possivelmente, mais adequados para as decisões finais. Quantos metros das margens dos rios devem ser mantidos/preservados? Quais áreas das propriedades particulares devem ser preservadas e, quais áreas devem ser conservadas? Questões como essas, fomentaram as discussões sobre o Novo Código Florestal do Brasil e também, demostraram a ampla necessidade do entendimento sobre a aplicação do conhecimento científico e tecnológico diante das necessidades de ordem social, econômica, financeira, industrial, cultural e ambiental.

Com essa visão entende-se que a ACT tem como finalidade da Educação Científica da Educação Básica tornar-se muito mais importante para o indivíduo em

\footnotetext{
${ }^{2} \mathrm{O}$ termo ideologias dominantes, aqui é usado conforme exposto em DEMO, P. Introdução à metodologia da ciência. 2. ed. São Paulo: Atlas, 1987.
} 
processo de formação e para a sociedade, não só pela sua importância para atrair recursos humanos para o progresso do conhecimento científico e tecnológico, mas também, oferecer ao cidadão, uma formação básica que o torne capaz de analisar e julgar a Ciência e a Tecnologia, valendo-se de argumentos não ingênuos, superficiais ou equivocados sobre a Ciência, a Tecnologia e as causas ambientais que vem sendo apresentadas à medida que o cenário da relação homem-natureza é desenhado desde a Revolução Industrial, iniciada na década de 1780, e que por sua vez, influenciou a consolidação da produção plenamente capitalista (SILVA; GASTAL, 2008; CHASSOT, 2010; VILCHES; GIL-PÉREZ; PRAIA, 2011; NAVARRO; FÖRSTER, 2012).

Segundo Auler (2003), a Educação Científica balizada pela ACT, pode trazer um melhor aproveitamento do ensino escolar para uma formação cidadã provida de importantes competências e habilidades para o sujeito atuar de forma mais crítica e conscientemente em questões de ordem ambiental, política, econômica, cultural e social do meio em que se encontra inserido, já que, tal perfil de Educação Científica almeja não só a capacitação do estudante para prosseguir os estudos em nível superior, mas também, formar cidadãos capazes de reconhecer e definir termos científicos, compreender ideias básicas do atual conhecimento científico, e ainda, saber aplicar tal conhecimento para se posicionar de forma crítica, reflexiva, consciente e atuante em situações atuais e reais.

Segundo os PCN para o Ensino Médio, Brasil (1999), o estudo das Ciências da Natureza e suas Tecnologias, necessita objetivar a constituição de competências e habilidades que permitam ao educando:

Compreender as ciências como construções humanas, entendendo como elas se desenvolvem por acumulação, continuidade ou ruptura de paradigmas, relacionando o desenvolvimento científico com a transformação da sociedade; entender o impacto das tecnologias associadas às Ciências Naturais na sua vida pessoal, nos progressos de produção, no desenvolvimento de conhecimento e na vida social (BRASIL, 1999, p. 107108).

Segundo as Orientações Curriculares Nacionais para o Ensino Médio, Brasil (2006), as relações didáticas entre as competências e os saberes escolares devem tratar a tecnologia como atividades humanas em que seus aspectos práticos e sociais, visam à solução de problemas concretos sem desconsiderar a base científica envolvida no processo de compreensão e construção dos produtos tecnológicos e as questões ambientais inerentes. Assim, tal documento destaca que: 
[...] a Alfabetização Científica e Tecnológica aponta claramente um dos grandes objetivos do ensino de ciências no nível médio: que os alunos compreendam a predominância de aspectos técnicos e científicos na tomada de decisões sociais significativas e os conflitos gerados pela negociação política (BRASIL, 2006, p. 47).

Auler (2003) afirma que a ACT com configuração curricular, pode ser apresentada como discurso e meio para a progressiva substituição da abordagem conceitual (predomínio no ensino informativo) pela abordagem temática (predomínio no ensino formativo), tendo em vista a necessidade de se ter outras opções de ensino que não seja necessariamente aquele que pauta-se preferencialmente no ensino propedêutico e na transmissão estanque de informações, para serem memorizadas pelos alunos sem necessariamente haver aprendizagem e formação de conhecimento próprio no educando.

Aqui, a definição de competência ancora-se no referencial teórico do Exame Nacional do Ensino Médio (ENEM), onde competências são modalidades estruturais da inteligência, ou seja, são ações e operações que se utiliza para estabelecer relações com e entre objetos, situações, fenômenos e pessoas que se deseja conhecer. Já as habilidades decorrem das competências adquiridas e referem-se ao plano imediato do saber fazer. Através das ações e operações, as habilidades aperfeiçoam-se e articulamse, possibilitando nova reorganização das competências (INSTITUTO NACIONAL DE ESTUDO E PESQUISAS EDUCACIONAIS ANÁSIO TEIXEIRA/ENEM Documento Básico, 2000).

Frente ao que foi exposto até aqui sobre a possível relação e interação entre a ACT e a EA, o presente artigo, que é parte dos estudos preliminares para uma tese de doutorado que objetiva compreender a ACT como finalidade da Educação Científica, e também, investigar fundamentos e métodos de ensino que possuam contribuir com a sua promoção para a Educação Básica, ressaltando aí, aqueles que também favorecem a promoção da EA, relata um estudo de abordagem quali-quantitativa, caracterizado como pesquisa descritiva e de campo, desenvolvido no segundo semestre do ano de 2012, com o objetivo de identificar percepções e concepções de alunos do Ensino Médio acerca de fatores relacionados à EA, que por sua vez, discorrem sobre as responsabilidades do Governo, da Sociedade, da Ciência e da Tecnologia, diante das questões da temática da degradação ambiental e como essas percepções e concepções se apresentam na primeira e última série de tal nível de formação.

O objetivo pretendido pelo estudo ancorou-se no pressuposto que acredita que o modelo de Educação Científica praticado nas escolas de Educação Básica - o chamado 
ensino tradicional -, pouco contribui com o processo formativo de percepções e concepções acerca da EA que, por um lado, seja menos ingênua e superficial, e por outro, seja mais capaz de contribuir significativamente com um modelo de formação cidadã ancorada em uma conscientização e postura crítica, reflexiva e atuante, frente às questões ambientais que aí se apresentam.

Entre os autores que o estudo buscou fundamentação para sua justificativa, objetivo e pressuposto, têm-se os trabalhos de: Cachapuz et al. (2005) em: A necessária renovação do ensino de ciências, e Carvalho (2011) em: Educação ambiental e formação do sujeito ecológico, entre outros autores que discutem, por um lado, sobre a emergência da ACT como meio para uma Educação Científica mais útil para todos os alunos/cidadãos, e por outro, autores que discutem a emergência da EA para a formação cidadã, e ainda, autores que vem publicando trabalhos com o objetivo de enfatizar essas duas vertentes de emergia e discussões, como é o caso, por exemplo, das publicações que carregam em seus cernes o enfoque Ciência-Tecnologia-Sociedade-Ambiente (o enfoque CTSA) como se vê, por exemplo, em Vilches; Gil-Pérez e Praia (2011) na publicação intitulada: De CTS a CTSA: educación por um futuro sostenible e em Acevedo-Díaz; Vázquez-Alonso e Manassero-Mas (2003) na publicação intitulada: Papel de la educación CTS em una alfabetización científica y tecnológica para todas las personas.

Por fim de tópico, salienta-se que aqui nesse artigo, adota-se a definição de percepção e concepção conforme discorre Cunha (2009) em sua tese de doutorado. Segundo essa autora, percepção é algo que está ligado a processos cognitivos, por meio da entrada de estímulos externos, produzindo significações que são internalizadas pelo sistema psicológico, mas que ainda não constituíram uma generalização, ou seja, um conceito. Nesse sentido, a concepção é o entendimento de uma situação, no nível conceitual, isso após a internalização dos significados produzidos pela percepção e de todas as transformações ocorridas no sistema psicológico. Assim, somente após o processo de significação e formação conceitual é que se está apto a conceber algo ou alguma coisa, ou seja, ter uma concepção do objeto e condições de resolver um problema, por exemplo.

\section{Metodologia}

A organização metodológica da pesquisa compôs-se das seguintes etapas: primeiro, o pesquisador, que também era professor do público alvo do estudo, 
selecionou por meio de sorteio uma turma de alunos da $1^{a}$ série e outra da $3^{a}$ série, ambas do Ensino Médio ${ }^{3}$, de uma escola pública estadual da periferia da cidade de Osasco, Região Metropolitana da Grande São Paulo, sendo a primeira turma composta por 19 meninos e 16 meninas com média de idade de 14 anos e, a segunda, composto por 13 meninos e 18 meninas com média de idade de 17 anos, para produzir um texto segundo o seguinte enunciado:

Elabore um texto expondo sua opinião sobre a(s) responsabilidade(s) que o Governo, a Sociedade, a Ciência e a Tecnologia podem ter sobre a questão da degradação ambiental e também, aponte sua opinião se seria possível usar os recursos naturais degradando a natureza o mínimo possível para que as gerações vindouras também possam usufruir desses recursos para o seu conforto e sobrevivência. Se você pensa que é possível, explique o como e, se pensas que não é possível, explique o porquê.

Após a produção dos textos, estes foram estudados segundo a análise de conteúdo proposta por Laurence Bardin, e assim, categorizados segundo quatro linhas de discussões sobre as questões ambientais: 1- o Governo; 2- a Ciência; 3- a Tecnologia; 4- a Sociedade; para serem analisados pela abordagem quali-quantitativa como se mostra mais adiante.

Tais categorias foram elaboradas conforme a aproximação do objetivo dessa pesquisa com as ideias de Cachapuz et al. (2005), Reigota (2009), Carvalho (2011) e Lourenço (2011), onde se defende a tese que a EA necessita ser sempre permeada pela ética e a politica e assim, implementada de forma a considerar as responsabilidades do Governo, da Ciência, da Tecnologia e da Sociedade, pois, do contrario, se estará fomentado uma EA acrítica, não reflexiva, superficial, ingênua e/ou equivocada quanto aos direitos, deveres e responsabilidades que cada setor da comunidade humana (a Ciência, a Tecnologia, a Sociedade, o Governo, a Indústria...) necessita assumir frente às questões ambientais e uso dos recursos naturais.

A escolha por produção de texto como instrumento de coleta de dados e informações se deve ao fato de ser esta modalidade de produção, algo bastante comum na prática dos professores dessas turmas de alunos, e também porque o pesquisador necessitou usar um instrumento de coleta de informações em que fosse permitido que os alunos expressassem livremente suas opiniões (concepções e percepções) de forma mais

\footnotetext{
${ }^{3}$ Segundo a Lei de Diretrizes e Bases da Educação Nacional, Lei no 9.394, de 20 de dezembro de 1996, o Ensino Médio é constituído por três anos, e compõe a última fase da Educação Básica no Brasil.
} 
ampla do que nas questões do tipo aberta em que cada enunciado das perguntas, de certa forma, pode induzir a manifestação, maior ou menor, de uma ou outra percepção.

Com tal instrumento de coleta de informações, pretendeu-se também oportunizar meios para o aluno da Educação Básica, em especial, o aluno do Ensino Médio, expor seus pontos de vistas e conhecimentos para, com isso, ser possível analisar a influencia que a escola por meio do ensino formal exerce sobre o processo formativo de percepções e concepções sobre as questões ambientais, para daí, confrontá-las com as ideias que preenchem as publicações sobre Educação Escolar e EA. Ou seja, expor/ressaltar o que é apregoado com o discurso da questão ambiental na literatura e o que, de fato, se forma em sala de aula no processo ensino-aprendizagem por meio da educação formal e sistematizada balizada pelo currículo oficial das escolas públicas que, no caso desse estudo, refere-se a uma escola pública Estadual de São Paulo.

Ao que tange a escolha da abordagem quali-quantitativa e que nesse estudo exerceu forte significado, se deve ao intercâmbio que a abordagem qualitativa permite entre esta e a abordagem quantitativa. Não que aqui pretendeu-se adotar o processo da simplificação e superficialidade de dois métodos complexos de pesquisa, esquecendo aí todo o discurso positivista sobre as pesquisas quantitativas, e sim aproveitar o viés quantitativo presente nas pesquisas qualitativas e vice-versa. Como discorrem Christian Laville e Jean Dione:

A partir do momento em que a pesquisa centra-se em um problema específico, é em virtude desse problema específico que o pesquisador escolherá o procedimento mais apto, segundo ele, para chegar à compreensão visada. Poderá ser um procedimento quantitativo, qualitativo, ou uma mistura de ambos. O essencial permanecerá: que a escolha da abordagem esteja a serviço do objeto de pesquisa, e não o contrário, com o objetivo de daí tirar, o melhor possível, os saberes desejados (LAVILLE e DIONNE, 1999, p. 43).

Por fim, o estudo qualitativo atrelado ao quantitativo, aqui adotado, está referenciado também em Lüdke e André (1986), que em seus trabalhos discutem a importância de se analisar as informações colhidas com o estudo quantitativo, também à luz do estudo qualitativo, principalmente, quando se trata de pesquisa relacionada a educação e o ensino escolar.

Ainda em relação ao contexto e sujeitos do estudo, salienta-se que no período em que o estudo foi realizado, os 66 alunos que dele participaram, na sua maioria, 
residiam na própria comunidade ${ }^{4}$ que circunda a Unidade Escolar, no entanto, tais alunos já estudaram anteriormente em outras escolas e assim possuem experiência de estudo em uma média de três escolas para o período que compõe sua formação escolar.

Nesta escola, é oferecido atendimento a 711 alunos do Ensino Fundamental e 829 alunos do Ensino Médio em três turnos. É alta a rotatividade de professores e alunos e também é alto o índice de reprovação parcial ou total, abandono escolar, e vandalismo ao patrimônio público por parte dos próprios alunos, principalmente em relação ao mobiliário (carteiras e cadeiras) e vidraças das janelas. Por fim, o espaço físico e os recursos didáticos deixam a desejar e as estratégias metodológicas baseiamse preferencialmente no ensino tradicional, onde a questão ambiental é trabalhada por todas as disciplinas priorizando, principalmente, a confecção de cartazes para serem expostos nos corredores que dão acesso às salas de aula.

\section{Resultados e Discussão}

Com base nas quatro categorias elaboradas para a análise do conteúdo dos textos produzidos pelos alunos, o estudo levantou aspectos acerca da EA que, segundo o que foi exposto na fundamentação bibliográfica, apontam para a necessidade do fomento à ACT como meio e contributo favorável à promoção da EA.

Inicialmente, o estudo identificou que, na sua maioria, os alunos de ambas as séries, em suas produções de textos, por um lado, não apontaram o Governo, a Ciência e a Tecnologia como responsáveis pela degradação ambiental e por outro, apontaram a Sociedade (o cidadão comum) como sendo o segmento de maior responsabilidade por tal degradação como mostra os percentuais da tabela 1 .

Tabela 1 - Sobre a responsabilidade pela degradação ambiental.

Percentuais de textos que de forma (in)direta, responsabilizam o Governo, a Ciência, a Tecnologia e a Sociedade pela degradação ambiental.

\begin{tabular}{lcc}
\hline Categorias & $\mathbf{1}^{\mathbf{a}}$ Série do Ensino Médio & $\mathbf{3}^{\mathbf{a}}$ Série do Ensino Médio \\
\hline 1- O Governo & $4 \%$ & $7 \%$ \\
2- A Ciência & $6 \%$ & $11 \%$ \\
3- A Tecnologia & $18 \%$ & $27 \%$ \\
4- A Sociedade & $98 \%$ & $87 \%$ \\
\hline
\end{tabular}

\footnotetext{
${ }^{4}$ Em tal comunidade não existe área de moradia informal (favelas).
} 
Em relação ao poder e/ou ações que o Governo, a Ciência, a Tecnologia e a Sociedade, possuem e/ou podem exercer para amenizar a degradação ambiental, os alunos, na sua maioria, apontaram o Governo como o segmento que possui maior poder para reduzir tal problema/degradação como mostra os percentuais da tabela 2.

Tabela 2 - Sobre a contribuição para reduzir a degradação ambiental.

Percentuais de textos que de forma (in)direta, apontaram o poder e/ou as ações que o Governo, a Ciência, a Tecnologia e a Sociedade, possuem e/ou podem realizar para reduzir a degradação ambiental.

\begin{tabular}{lcc}
\hline Categorias & $\mathbf{1}^{\text {a }}$ Série do Ensino Médio & $\mathbf{3}^{\text {a Série do Ensino Médio }}$ \\
\hline 1- O Governo & $88 \%$ & $79 \%$ \\
2- A Ciência & $10 \%$ & $16 \%$ \\
3- A Tecnologia & $10 \%$ & $21 \%$ \\
4- A Sociedade & $21 \%$ & $33 \%$ \\
\hline
\end{tabular}

No entanto, esse poder percebido e concebido pelos alunos ao Governo é, segundo estes, o poder expresso por força de lei, coerção e punições como mostram as seguintes transcrições de trechos dos textos de alguns alunos ${ }^{5}$ :

[...] o governo municipal, estadual e federal, devem fazer leis para punir mais as pessoas que não respeitam a natureza $[\ldots] 3-1^{\mathrm{a}}$.

[...] todo mundo que joga lixo nas ruas devem ser punidos pagando uma multa e fazendo trabalhos voluntários [...] $22-3^{\mathrm{a}}$.

[...] é preciso colocar mais polícias nas ruas para fiscalizar as pessoas que não cuidam da natureza e do meio ambiente e joga lixo nas ruas $[\ldots] 10-3^{a}$.

[...] quem joga lixo, garrafa plástica, sacolinhas de plástico nas ruas, deve ir para a cadeia $[\ldots] 4-3^{a}$.

[...] a única forma de conscientizar as pessoas é com punição forte para que elas aprendam como deve cuidar da natureza [... $35-1^{\mathrm{a}}$.

[...] somente com a força da lei é que iremos resolver o problema da degradação ambiental [...] $29-3^{\text {a }}$.

[...] as pessoas destroem a natureza jogando lixo nas ruas e nos rios, cortando árvores porque não são punidas, se o prefeito punir, elas param de fazer isso $[\ldots] 16-1^{\mathrm{a}}$.

[...] o poder público deve multar as pessoas que jogam lixo nas ruas e nos rios porque somente quando doe no bolso e que as pessoas aprendem [... $25-1^{\mathrm{a}}$.

Frente às ideias expostas nessas transcrições, percebe-se que os conhecimentos acerca da ética e dos princípios da democracia, da cidadania e da responsabilidade

\footnotetext{
${ }^{5} \mathrm{O}$ texto de cada aluno da $1^{\mathrm{a}}$ série do Ensino Médio foi enumerado de 1 a 35 e os da $3^{\mathrm{a}}$ série foram enumerados de 1 a 31. Números equivalentes à quantidade de alunos de cada turma. Assim, nas transcrições de parte dos textos, os alunos serão identificados da seguinte forma: $1-3^{\mathrm{a}}$ onde, ' 1 ' referese ao número que o texto do aluno recebeu e, $3^{\mathrm{a}}$, refere-se a série do Ensino Médio que o aluno estuda.
} 
social (individual e coletiva), sobre as questões ambientais, ainda estão significativamente ausentes no processo de formação básica desses alunos.

Se concebermos a EA como educação política onde a ética ocupa um papel de fundamental importância em tal processo educacional, assim como apregoa Reigota (2009), então ideias como as que foram apresentadas nas transcrições anteriores e oriundas de trechos dos textos dos alunos, necessitam ser urgentemente superadas, já que a coerção como meio para se conseguir comportamentos e atitudes considerados por outrem "adequados" nada interessa à EA que pauta-se na ética e na democracia como balizas de perspectiva para a formação do sujeito consciente e responsável acerca da necessária relação homem-natureza. Dessa forma, o termo ética aqui empregado, ancora-se na ideia que diz respeito à capacidade que o sujeito necessita possuir para atuar e tomar decisões de forma correta e deliberada.

Como expõe Cortela (2011), essa tomada de decisão pelo sujeito, para ser de fato pautada na ética e na democrática, necessita originar-se do produto da reflexão acerca de três questões básicas: eu quero? eu devo? eu posso? isso porque, segundo esse autor, a ética tem um pressuposto: a possibilidade de escolha. A ética pressupõe a possibilidade de decisão em que o sujeito assume deliberadamente suas opções. Ética pressupõe a possibilidade de opções livres de coerção, doutrinamento e/ou fanatismo ideológico.

Como afirmam Reigota (2009) e Carvalho (2011), a conscientização sobre o como, o porquê e o quando acerca da postura correta na relação homem-natureza, necessita ser algo inerente ao conhecimento próprio do sujeito, onde este, influenciado/ajudado pelo ensino (formal e não formal), apresenta capacidade de ações deliberadas e adequadas em relação ao meio ambiente, tanto no nível individual e local como no nível coletivo e planetário.

Ainda sobre as transcrições apresentadas anteriormente, fica explícito a necessidade, nesses alunos, de uma compreensão mais alargada sobre o que, de fato, é necessário como atuação do Governo em relação às questões da degradação ambiental. Com o estudo do conteúdo dos textos, foi possível perceber que, enquanto são totalmente ausentes nas produções desses alunos, percepções e concepções que questionam a ação do Governo sobre, por exemplo, o porquê de este incentivar tanto a compra do carro próprio, ou então por que as politicas públicas para a melhoria e expansão dos transportes coletivos ainda são significativamente tímidas se comparado a importância que esse tipo de transporte representa para amenizar a degradação 
ambiental, ideias ingênuas, superficiais e paliativas sobre as questões ambientais, prevalecem em todas as produções dos textos como mostram as seguintes transcrições de trechos desses textos:

[...] tanto faz usar o carro ou o ônibus, os dois poluem do mesmo jeito porque os dois tem motor e queima combustível, mas eu acho que é mais vantagem usar o carro próprio porque é mais confortável e quase sempre, a gente chega mais rápido [...] $4-1^{\mathrm{a}}$.

[...] eu penso que se todo mundo for usar o transporte coletivo, não vai dar certo porque vai ficar muito lotado mais do que já é $[\ldots] 30-1^{\text {a }}$.

[...] no fundo, no fundo, quem pode comprar um carro, acaba ajudando as pessoas que precisam andar de ônibus porque, quem anda de carro deixa o lugar no ônibus para quem não pode comprar um carro [...] $19-3^{\mathrm{a}}$.

[...] a única forma de resolver o problema da poluição do ar é todo mundo usar bicicleta para ir para o trabalho, e outros lugares que precisar, mesmo que seja longe, eu acho que as pessoas devem se conscientizar e usar a bicicleta para ajudar a natureza $[\ldots] 25-3^{\mathrm{a}}$.

Considerando a expressiva quantidade de trabalhos que vêm sendo promovidos pelas escolas, pela mídia e por praticamente todos os segmentos da sociedade sobre as questões ambientais, as ideias apresentadas nas últimas transcrições tornam-se preocupantes e também, nos remete a Leff (2010), onde este também pontua que, considerando o nível de formação do sujeito, quando a compreensão do fato/fenômeno ocorre de forma incompleta por consequência da deficiência da atuação do ensino (incluindo aí questões de ordem metodológicas e epistemologias), pressupostamente, o sujeito tende a, em um momento, apresentar uma concepção (inclusive as óbvias) de um fenômeno, e em outro momento apresentar concepções que vão totalmente ao contrário daquelas apresentadas anteriormente, mas que não são evoluções das primeiras, e sim concepções confusas e contraditórias por conta da falta de uma base de conhecimento suficientemente adequado sobre o fato/fenômeno.

Os alunos afirmaram que tanto faz usar o carro ou o ônibus porque ambos poluem do mesmo jeito. Afirmaram também que quem anda de carro acaba ajudando quem precisa andar de ônibus. Essas concepções podem até ser consideradas reais se for levado em consideração, pressupostamente, o nível de EA desses alunos. Não se pode negar que um carro com cinco lugares e um ônibus com cinquenta, poluem o meio ambiente porque emitem gases poluentes, inclusive aqueles, segundo Pinotti (2010), movidos por biocombustível. Não se pode negar que usar o carro próprio pode ser mais confortável do que usar o ônibus, então como alargar essas concepções a ponto de o sujeito compreender que o ônibus pode ser considerado menos poluente e mais 
vantajoso para todos, sem impor ao sujeito esses entendimentos por coerção ou por transmissão estanque de informações para serem memorizadas ou seguidas, muitas vezes, de forma acrítica, incompleta e/ou confusa?

Frente ao que foi exposto nos dois últimos parágrafos, acredita-se que a Educação Científica balizada pela e para a ACT pode contribuir como uma ferramenta e meio facilitador para levar o aluno ao entendimento e atitude que se deseja com a EA, por considerar, como afirmam Cachapuz et al. (2005) e Chassot (2010), a importância de se estudar e entender a degradação ambiental e as suas possíveis formas de reversão, considerando o potencial de cada parte frente ao resultado do todo, ou seja, considerar os aspectos inerentes a compreensão de três aspectos: o mecanismo de funcionamento da natureza, a relação homem-natureza e a relação homem-homem.

Ao mencionar esses três aspectos, tem-se a pretensão de, fundamentando-se em Chassot (2010), enfatizar que toda ação de ensino (formal ou informal, disciplinar ou interdisciplinar) que visa a EA, necessita dotar-se de um significativo repertório de conhecimento científico, sociológico, filosófico, político e econômico, para assim ser menos vulnerável as armadilhas do fanatismo ideológico e do vazio epistemológico.

Aprofundando um pouco mais a ideia apresentada no ultimo parágrafo, salientase que outro aspecto que o estudo percebeu como preocupante quando se almeja uma EA pautada em uma compreensão adequada sobre como a espécie humana se relaciona com a natureza e com as outras espécies (relação homem-natureza) assim como discorre Reigota (2009), Carvalho (2011) e Soffiati (2011), diz respeito às concepções dos alunos, onde se observa o predomínio da visão dogmática e romântica sobre a natureza e as questões ambientais. Em $81 \%$ das produções dos textos do grupo de alunos da primeira série do Médio e, $74 \%$ das produções dos alunos da $3^{\mathrm{a}}$ série, apontaram direta ou indiretamente tais visões românticas e dogmáticas, como mostram as seguintes transcrições:

[...] a natureza é algo de deus é por isso devemos respeitar a natureza, o meio ambiente, os animais e tudo que deus criou [...] $23-1^{\mathrm{a}}$.

[...] precisamos urgente aprender a usar e cuidar da natureza porque se ela acabar, nos iremos ter muita dificuldade para viver [...] $15-3^{\mathrm{a}}$.

[...] as árvores nos dá frutos, flores e sombra, além de purificar o ar para a gente respirar, tudo isso exige que a gente cuide da natureza $[\ldots] 8-1^{\mathrm{a}}$.

[...] respeitar a natureza é como uma religião, ou você segue fielmente ou não segue, e se você não seguir, você terá muitas consequências ruins como tempestades, aquecimento global, falta de água para beber e falta de ar puro para respirar $[\ldots] 27-1^{\mathrm{a}}$.

[...] a natureza é uma coisa muito bela e boa para nós e por isso devemos cuidar dela para tudo continuar com muita beleza $[\ldots] 31-3^{\mathrm{a}}$. 
[...] as árvores merecem ser bem cuidadas porque elas nos dão frutos, sombra e produzem o ar que a gente respira $[\ldots] 7-3^{\mathrm{a}}$.

As concepções expostas nessas últimas transcrições, na percepção desse estudo, é o que mais se aproxima das ideias que esse estudo defende sobre a necessidade da ACT. Assim como discorre Chassot (2010), as percepções e concepções que os alunos expuseram em suas produções muito tem à ver com o conhecimento popular e religioso, mostrando aí que o conhecimento científico pouco ou nada ocupa lugar nas argumentações e fundamentações acerca da organização/constituição da natureza e todas as relações ecológicas que nesta se dá por força das leis naturais.

Assim como discorre Jiménez-Aleixandre (2004), Cachapuz et al. (2005) e Chassot (2010), a EA necessita ser pautada claramente em uma compreensão correta da composição e funcionamento da natureza para não se correr o risco de se cair em concepções ingênuas ou dogmáticas, já que, como afirma Portilho (2009), para a constituição de uma ideia (conhecimento, concepção) buscamos respaldo em nossos conhecimentos anteriores que pode ser tanto o conhecimento religioso, científico, popular ou do senso comum.

Ainda na visão de Chassot $(2008 ; 2010)$, o sujeito (envolve aí o aluno e o professor) necessita entender que não é bom considerar um ou outro conhecimento como o correto de forma a ser possível descartar totalmente os outros. Da mesma forma, é necessário entender que o conhecimento científico usado de forma ética e democrática pode e muito contribuir para a EA, e assim tal conhecimento necessita fazer parte do repertório de concepções do aluno para que este usufrua de um número maior de ferramentas para respaldar suas ideias, opiniões e opções em geral.

Ao que tange as ideias para anemizar o problema da degradação ambiental e o uso do meio ambiente conforme o que foi exposto no enunciado para a produção dos textos, o público envolvido do estudo expressaram as seguintes opiniões/sugestões como mostram as seguintes transcrições de parte dos seus textos/produções:

[...] é possível reduzir a degradação ambiental cuidando mais das árvores, dos rios e dos animais assim a natureza não vai acabar [...] $2-1^{\mathrm{a}}$.

[...] dá para resolver o problema da destruição da natureza com mais conscientização das pessoas [...] $10-1^{\mathrm{a}}$.

[...] para ajudar o meio ambiente necessitamos ensinar as pessoas a como cuidar da natureza porque ela é o nosso maior bem para viver [...] $17-3^{\mathrm{a}}$.

[...] o governo precisa fazer mais obras para acabar com as enchentes porque as enchentes agridem a natureza e destrói tudo, assim o caminho para resolver o problema da destruição da natureza é só acabar com as enchentes e não deixar as pessoas morar próximo dos rios e dos morros [... $2-3^{\mathrm{a}}$. 


\section{Conclusão}

Os resultados alcançados com o estudo revelam que as percepções e concepções dos alunos envolvidos no estudo são, na sua grande maioria, ingênuas, reduzidas e/ou equivocadas, porque são, quase que em sua totalidade, fundamentadas em informações incompletas, visão romântica e dogmática sobre a natureza e o meio ambiente, aceitação acrítica sobre as responsabilidades do Governo, da Ciência e da Tecnologia, e ainda, visão de EA como doutrinamento.

Mediante a vertente de discussão sobre a EA que o estudo recortou para discutir, então conclui-se que a ACT como meio e finalidade da Educação Científica para a Educação Básica pode também ser no ensino formal, um importante facilitador da EA que atualmente se necessita e se deseja para a sociedade contemporânea.

Por fim, salienta que, sendo o pesquisador também professor do público alvo do estudo, os resultados foram apresentados a direção, coordenação, professores, pais e alunos da escola em que o estudo foi realizado para daí, em grupo, ser discutido ações de ensino e aprendizagem que por sua vez, possam ir ao encontro das necessidades educacionais que foram expostas por ocasião da realização do estudo.

\section{Referências}

ACEVEDO-DÍAZ, J. A.; VÁZQUEZ-ALONSO, A.; MANASSERO-MAS, M. A. Papel de la educación CTS em una alfabetización científica y tecnológica para todas las personas. Revista Eletrónica de Enseñanza de las Ciencias, v. 2, n. 2, p. 80-111, 2003. Disponível em: $<$ http://reec.uvigo.es/volumenes/volumen2/REEC 22 1.pdf $>$. Acesso em: 20 abr. 2013.

AULER, D. Alfabetização científica-tecnológica: um novo "paradigma”? Ensaio Pesquisa em Educação em Ciências, v. 5, n. 1, p. 1-16, 2003. Disponível em: <http://www.fae.ufmg.br/ensaio/v5_n1/516.pdf>. Acesso em: 20 abr. 2013.

BARBIERI, J. C. Desenvolvimento e meio ambiente: as estratégias de mudanças da agenda 21. 10. ed. Petrópolis, RJ: Vozes, 2009.

BRASIL. Ministério da Educação. Secretaria de Educação Fundamental. Parâmetros curriculares nacionais: Ciências Naturais. Brasília, DF: MEC/SEF, 1998a.

. Ministério da Educação. Secretaria de Educação Fundamental. Parâmetros curriculares nacionais: terceiro e quarto ciclos: apresentação dos temas transversais. Brasília, DF: MEC/SEF, 1998b.

Ministério da Educação. Secretaria de Educação Média e Tecnológica. Parâmetros curriculares nacionais para o ensino médio. Brasília, DF: MEC/Semtec, 1999. 
Ministério da Educação. Secretaria de Educação Média e Tecnológica.

Ciências da natureza, matemática e suas tecnologias: orientações curriculares para o ensino médio. Brasília, DF: MEC/Semtec, 2006. v. 2.

CACHAPUZ, A. et al. (Orgs.). A necessária renovação do ensino das ciências. São Paulo: Cortez, 2005.

CARVALHO, I. C. M. Educação ambiental e formação do sujeito ecológico. 5. ed. São Paulo: Cortez, 2011.

CHASSOT, A. Sete escritos sobre educação e ciências. São Paulo: Cortez, 2008.

Alfabetização científica: questões e desafios para a educação. 5. ed. Ijuí: Unijuí, 2010.

CORTELA, M. S. A escola e o conhecimento: fundamentos epistemológicos e políticos. 14. ed. São Paulo: Cortez, 2011.

CUNHA, M. B. A percepção de ciências e tecnologia dos estudantes de ensino médio e a divulgação científica. 2009. 363 f. Tese (Doutorado em Ensino de Ciências e Matemática) - Faculdade de Educação da Universidade de São Paulo, São Paulo, 2009.

DEMO, P. Educar pela pesquisa. 9. ed. Campinas, SP: Autores Associados, 2011.

FERRAROTTI, F. A revolução industrial e os novos trunfos da ciência, da tecnologia e do poder. In: MAYOR, F.; FORTI, A. (Org.) Ciência e poder. Campinas, SP: Papirus; Brasília: Unesco, 1998. p. 45-62.

FOUREZ, G. Alfabetización científica y tecnológica: acerca de las finalidades de la enseñanza de las ciências. 1. ed. 3 reimp. Buenos Aires: Colihue, 2005.

INSTITUTO NACIONAL DE ESTUDOS E PESQUISAS EDUCACIONAIS ANÍSIO TEIXEIRA. ENEM (2000) - documento básico. Disponível em:

<http://www.inep.gov.br/enem_documentobascio>. Acesso em: 02 mar. 2011.

JIMÉNEZ-ALEIXANDRE, M. P. La catástrofe del prestigie: racionalidade crítica versus racionalidad instrumental. Cultura y Educación. v. 16, n. 3, p. 305-319, 2004.

LAVILLE, C., DIONNE, J. A construção do saber. Porto Alegre: Artmed, 1999.

LEFF, E. Epistemologia ambiental. 5. ed. São Paulo: Cortez, 2010.

LOURENÇO, C. F. B. Educação ambiental e movimentos sociais na construção da cidadania ecológica e planetária. In: , LAYRARGUES, P. P., CASTRO, R. S.

Educação ambiental: repensando o espaço da cidadania (Orgs.). 5. ed. São Paulo: Cortez, 2011.

LÜDKE, M.; ANDRÉ, M. E. D. A. Pesquisa em educação: abordagens qualitativas. São Paulo: EPU, 1986. 
NAVARRO, M. B.; FÖRSTER, C.E. Nível de alfabetizazión científica y actitudes hacia la ciência en estudiantes de secundaria: camparaciones por sexo y nível socioeconómico. Pensamiento Educativo. Revista de Investigación Educacional Latinoamericana. v. 49, n. 1, p. 1-17, 2012. Disponível em: $<$ http://pensamientoeducativo.uc.cl/files/journals/2/articles/507/public/507-1236-1PB.pdf $>$. Acesso em: 20 de fev. 2013.

PINHEIRO, N. A. M.; SILVEIRA, R. M. C. F.; BAZZO, W. A. O contexto científicotecnológico e social acerca de uma abordagem crítico-reflexivo: perspectiva e enfoque. Revista Iberoamericana de Educación. n. 49/1, 2009.

PINOTTI, R. Educação ambiental para o século XXI: no Brasil e no mundo. São Paulo: Blucher, 2010.

PORTILHO. E. Como se aprende? estratégias, estilos e metacognição. Rio de Janeiro: Wak Editora, 2009.

REIGOTA, M. O que é educação ambiental. 2. ed. São Paulo: Brasiliense, 2009.

SANTOS, W. L. P.; MORTIMER, E. F. Tomada de decisão para a ação social responsável no ensino de ciências. Ciências \& Educação, v. 7, n. 1, p. 95-111, 2001.

Significado da educação científica com enfoque CTS. In: ; AULER, D.

(Orgs.). CTS e educação científica: desafios, tendências e resultados de pesquisa. Brasília: Editora Universidade de Brasília, 2011. p. 21-47.

SASSERON, L. H., CARVAHO, A. M. P. Alfabetização científica: uma revisão bibliográfica. Investigações em Ensino de Ciências. v. 16, n. 1, p. 59-77, 2011.

SILVA, C. C.; GASTAL, M. L. Ensinando ciência e ensinando a respeito da ciência. In: PAVÃO, A. C.; FREITAS, D. (Orgs.). Quanta ciência há no ensino de ciências. São Paulo: EduFSCar, 2008. p. 35-44.

SOFFIATI, A. Fundamentos filosóficos e históricos para o exercício da ecocidadania e ecoeducação. In: BAETA, A. M. B. et al. (Orgs.). Educação ambiental: repensando o espaço da cidadania. 5. ed. São Paulo: Cortez, 2011. p. 27-72.

TOZONI-REIS, M. C. Pesquisa em educação ambiental na universidade: produção de conhecimento e ação educativa. In: TALAMONI, J. B.; SAMPAIO, A. C. (Orgs.).

Educação ambiental: da prática pedagógica à cidadania. São Paulo: Escrituras, 2003. p. $9-19$.

UNESCO. A ciência para o século XXI: uma nova visão e uma base de ação. Brasília: UNESCO, ABIPTI, 2003.

VILCHES, A., GIL-PÉREZ, D.; PRAIA J. De CTS a CTSA: educación por um futuro sostenible. In: SANTOS, Wildson L. P., AULER, D. (Orgs.). CTS e educação científica: desafios, tendências e resultados de pesquisa. Brasília: Editora Universidade de Brasília, 2011. p. 185-209. 